\title{
Paeoniflorin ameliorates acute myocardial infarction of rats by inhibiting inflammation and inducible nitric oxide synthase signaling pathways
}

\author{
CHANG CHEN $^{1}$, PING DU ${ }^{2}$ and JUNJIE WANG ${ }^{2}$ \\ Departments of ${ }^{1}$ Emergency and ${ }^{2}$ Cardiology, The First Affiliated Hospital of Dalian Medical University, \\ Dalian, Liaoning 116011, P.R. China
}

Received July 30, 2014; Accepted April 28, 2015

DOI: $10.3892 / \mathrm{mmr} .2015 .3870$

\begin{abstract}
Paeoniflorin (PF) is the main active component of the commonly used Traditional Chinese Medicine peony, Paeonia Suffruticosa. PF has diverse biological functions and exhibits anti-oxidative, anti-inflammatory and anti-apoptotic activity. Inducible nitric oxide synthase (iNOS) is a catalyzing enzyme that is involved in the synthesis of nitric oxide (NO). $\mathrm{NO}$ has an important regulatory role in the cardiovascular, immune and nervous systems. PF has previously been demonstrated to inhibit the gene expression of iNOS. The present study aimed to identify a potentially novel cytoprotective function of PF, and to elucidate its effects against myocardial ischemic damage in a rat model of acute myocardial infarction (AMI). PF was able to significantly decrease the myocardial infarct size as well as the activities of creatine kinase (CK), the $\mathrm{MB}$ isoenzyme of $\mathrm{CK}$, lactate dehydrogenase and cardiac troponin T. In addition, in the PF-treated groups, the expression levels of tumor necrosis factor- $\alpha$, interleukin (IL)-1 $\beta$, IL- 6 and nuclear factor- $\kappa \mathrm{B}$ were markedly inhibited. Furthermore, treatment with PF inhibited the activities and protein expression levels of iNOS. Decreased caspase-3 and caspase-9 activities were also observed in the AMI rat model treated with various doses of PF. The results of the present study indicated that the cardioprotective effects of PF may be associated with the inhibition of inflammation and iNOS signaling pathways.
\end{abstract}

\section{Introduction}

Acute myocardial infarction (AMI) is a type of myocardial ischemia caused by acute coronary and persistent hypoxic ischemia. AMI is associated with electrocardiographical

Correspondence to: Dr Junjie Wang, Department of Cardiology, The First Affiliated Hospital of Dalian Medical University, 222 Zhongshan Road, Dalian, Liaoning 116011, P.R. China E-mail: junjiew@126.com

Key words: inducible nitric oxide synthase, paeoniflorin, acute myocardial infarction, cardioprotection, anti-inflammatory changes, which may be complicated by cardiac arrhythmia, shock or heart failure, and are often life-threatening (1). AMI causes initial structural changes to the infarcted and non-infarcted areas of the heart, followed by expansion of the ventricles, resulting in cardiac dysfunction (2). The formation of myocardial fibrosis and scar tissue following AMI is an important pathological alteration that induces heart failure. The formation of the myocardial scar is associated with the speed of myocardial ischemia, size and location of infarct-associated vessels, and the presence of reperfusion (3). Surrounding the infarcted area and in the area away from normal tissue, ventricular reconstruction is conducted to maintain cardiac output and to lower wall tension. This adaptation process includes left ventricular dilatation, left ventricular hypertrophy, myocardial cell hypertrophy and fibrosis of the intercellular matrix. Previous pharmacological studies have indicated that numerous types of cardioprotective drugs treat cardiovascular disease via anti-inflammatory and anti-oxidant signaling pathways (4).

Recently, an upregulated inflammatory response was identified as being essential for the pathophysiology of AMI (5). Overexpression of inflammatory cytokines have been identified in the adipose tissue of rat models of AMI, including tumor necrosis factor- $\alpha$ (TNF- $\alpha$ ), interleukin (IL)-1 $\beta$ and IL-6 (6). Furthermore, TNF- $\alpha$ has been shown to be overexpressed in the muscle tissue of obese humans or mice (7). TNF- $\alpha$ is able to increase the phagocytosis of neutrophils, promote the secretion of IL-1 and IL- 6 by endothelial cells, and strengthen the adhesion of neutrophils and endothelial cells, thereby stimulating local inflammatory expansion and the response to AMI $(8,9)$. Of note, TNF- $\alpha$ is responsible for mediating the cytoprotective effects through nuclear factor $(\mathrm{NF})-\kappa \mathrm{B}$. Since $\mathrm{NF}-\kappa \mathrm{B}$ mediates cytoprotective responses, NF- $\kappa \mathrm{B}$ activation is considered to exhibit cytoprotective effects in AMI (2). Accordingly, the upregulation of anti-inflammatory signaling pathways may have cardioprotective effects in rats following AMI.

Furchgott et al (10) and Palmer et al (11) demonstrated that vascular endothelial cells are able to synthesize and secrete endothelium-derived relaxing factor, which is also known as nitric oxide (NO). NO is produced in a multi-step oxidation and reduction reaction in which L-arginine is catalyzed 
by nitric oxide synthase (NOS) and reacts with oxygen molecules. NOS can be broadly divided into two types: Constructive nitric oxide synthase and inducible nitric oxide synthase (iNOS). iNOS is expressed not only in immune cells, including macrophages and neutrophils, but also in fibroblasts, keratinocytes, endothelial cells and vascular smooth muscle cells (12). Excessive NO is usually accompanied by inflammation and immune disorders, pain, neurological disorders, atherosclerosis and cancer (13). Following myocardial infarction in mice, increased expression levels of iNOS have been detected, which results in the induction of excessive NO, decreased cardiac function and increased mortality (14). Therefore, iNOS inhibitors may be used clinically in order to reduce iNOS expression and decrease NO production. iNOS and NO exist in the cytoplasm of all tissues, which is one of the important indicators for AMI diagnosis. Therefore, it was hypothesized that inhibiting the iNOS signaling pathways may have a cardioprotective effect in a rat model of AMI (15).

Paeoniflorin $(\mathrm{PF})$ is a monoterpene glycoside compound. Recently, PF has been shown to increase the levels of superoxide dismutase and reduce the malondialdehyde content in ischemic brain tissue (16). PF has a significant anti-inflammatory effect, which can reduce the abnormally increased phagocytic function of peritoneal macrophages in models of rheumatoid arthritis and lower the levels of TNF- $\alpha$, IL-1 and IL-6 $(17,18)$. Previous studies have also demonstrated that PF is able to inhibit the gene expression of iNOS $(17,19)$. However, whether PF can ameliorate AMI in rats remains to be elucidated. Since $\mathrm{PF}$ has a critical role in the protection against ischemic insults, the present study hypothesized that PF may provide a potential therapeutic target for cardioprotection. Therefore, the present study aimed to determine the cytoprotective effects of PF in a rat model of AMI, and to further explore the potential underlying mechanisms.

\section{Materials and methods}

Ethical approval. All of the experimental procedures of the present study were approved by the First Affiliated Hospital of Dalian Medical University (Dalian, China). The present study was performed in accordance with the recommendations in the Guide for the Care and Use of Laboratory Animals of the National Institutes of Health (Bethesda, MD, USA).

Experimental animals. A total of 30 Sprague-Dawley rats (8-10 weeks-old; weighing 250-300 g) were purchased from the Experimental Animal Center of The First Affiliated Hospital of Dalian Medical University (Dalian, China), housed under a $12 \mathrm{~h} / 12 \mathrm{~h}$ dark and light cycle, at $23 \pm 1^{\circ} \mathrm{C}$ with a relative humidity of $50 \%$. The rats were allowed to acclimatize in plastic cages with ad libitum access to food and clean drinking water.

Animal models. All experimental rats were subjected to surgery following anesthesia with sodium pentobarbitone $[40 \mathrm{mg} / \mathrm{kg}$ intraperitoneally; Tiangen Biotech (Beijing) Co., Ltd., Beijing, China]. The rats were bound to a rat table, and under anesthesia, the trachea of each rat was separated, intubated and artificially ventilated with a respirator (S9 VPAP ST; ResMed Inc., Bella Vista, NSW, Australia) at a tidal volume of 4-5 $\mathrm{ml}$ per breath.
Needle electrodes were connected to a normal electrocardiogram device (ECG1200G; Contec Medical Systems Co., Ltd., Qinhuangdao, China). The device was subcutaneously penetrated into four limbs of the rat via a transducer attached to a multi-channel recorder. A left sternal border thoracotomy was performed between the third and fourth intercostal spaces. The pericardium was removed, separating the heart and blood vessels on the left ventricular surface. The left anterior descending coronary artery was ligated below the left atrial appendage, using a 1-2 mm 5-0 silk suture. Penicillin and streptomycin were then injected into the rats, in order to prevent infection. The rat model of AMI was prepared by ligation of the left anterior descending coronary artery. A total of six rats underwent a sham surgery, which involved the identical surgical procedure without the coronary artery ligation. A total of 24 rats successfully underwent the experimental surgery. Successful establishment of the AMI model was confirmed by regional cyanosis of the myocardial surface, which was represented by ST-segment elevation (SPR-838; Millar Instruments, Houston, TX, USA) and analyzed using analysis software (PVAN 2.9; Millar Instruments) (20).

Group design and drug administration. The chemical structure of PF is presented in Fig. 1. PF (Sigma-Aldrich, St. Louis, MO, USA; 98\% purity; 5, 10 and $20 \mathrm{mg} / \mathrm{kg}$ ) was dissolved in physiological saline. The 30 rats were randomized into five groups, each containing six rats: Sham group, Vehicle group and PF treatment groups (various doses of PF were used: 5, 10 and $20 \mathrm{mg} / \mathrm{kg}$ ) (21). The sham group was the control group that did not undergo the coronary ligation. The vehicle group underwent the AMI procedure prior to injection with the same volume of physiological saline (Luye Pharma Group Ltd., Dalian, China). The PF treatment groups underwent the AMI procedure prior to injection with PF through the tail vein. PF and physiological saline were injected for seven consecutive days. The dosage and dosing frequency were determined on the basis of a previous study (22). The rats underwent the coronary ligation $30 \mathrm{~min}$ after the last administration.

Infarct size measurement. Rats were anesthetized by injecting chloral hydrate. All experimental rats were sacrificed by decapitation. The hearts were immediately cannulated via the aorta and washed with physiological saline. Six hours after the coronary artery was ligated, the left ventricles were incubated at $-80^{\circ} \mathrm{C}$ for $5 \mathrm{~min}$, and then sliced into $2-\mathrm{mm}$ sections. Infarct size was estimated as a percentage of area at risk following an the incubation with 2,3,5-triphenyltetrazolium chloride (1.5\%; Sigma-Aldrich) $(23,24)$. The area of the heart without color indicated ischemic heart muscle, whereas the area stained brick red indicated normal myocardium. The size of the infarct area was measured by the volume and weight as a percentage of the left ventricle.

Measurement of creatine kinase (CK), $M B$ isoenzyme of $C K$ $(C K-M B)$, lactate dehydrogenase $(L D H)$ and cardiac troponin $(c \operatorname{Tn} T)$ levels. Rat serum samples were taken from the vena cava $6 \mathrm{~h}$ after the ligation of the coronary artery. The samples were centrifuged at $3,500 \mathrm{x}$ g for $5 \mathrm{~min}$ in order to determine the levels of myocardial-specific enzymes: CK, CK-MB, $\mathrm{LDH}$ and cTnT. The CK activities were determined using a 
creatine kinase assay kit (cat. no. A032; Nanjing Jiancheng Bioengineering Institute, Nanjing, China). The activities of CK-MB and serum cTnT were quantified by CK-MB and cTnT ELISA (cat. nos. ARB10700 and ARB13662; Rapidbio, West Hills, CA, USA). A colorimetric assay was used to analyze the activities of $\mathrm{LDH}$, according to the manufacturer's instructions (Nanjing Jiancheng Bioengineering Institute, China).

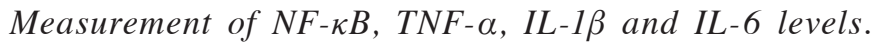
Following the 3 -h ischemic period, whole blood samples were allowed to clot in a serum separator tube for $30 \mathrm{~min}$. The serum samples were then centrifuged at $1,000 \mathrm{x}$ g for $25 \mathrm{~min}$, and were maintained at $-80^{\circ} \mathrm{C}$ until further use. For the measurement of the serum levels of NF- $\kappa$ B, TNF- $\alpha$, IL-1 $\beta$ and IL- 6 , a commercially available ELISA kit was used (Uscnlife, Wuhan EIAab Science Co., Ltd, Wuhan, China), according to the manufacturer's instructions.

Western blot analysis for the detection of iNOS protein. Western blot analysis was performed for the detection of iNOS protein expression (25). Proteins were extracted from the cardiac samples, which had been stored at $-80^{\circ} \mathrm{C}$. Briefly, the samples were homogenized in ice-cold lysis buffer [Tiangen Biotech (Beijing) Co., Ltd.]. Following centrifugation at $13,200 \mathrm{xg}$ for $20 \mathrm{~min}$ at $4^{\circ} \mathrm{C}$, the supernatant was collected and total protein levels were quantified using a bicinchoninic acid (BCA) protein assay kit (Beyotime Institute of Biotechnology, Haimen, China). Protein samples (50-70 $\mu \mathrm{g}$ ) were then separated by SDS-PAGE (BeastBio, Shanghai, China) and transferred onto nitrocellulose membranes (Millipore Corporation, Bedford, MA, USA). The membranes were blocked with 5\% non-fat milk (Yili Group., Hohhot, China) and $0.1 \%$ Tween 20 [Tiangen Biotech (Beijing) Co., Ltd.] in $10 \mathrm{mM}$ Tris- $\mathrm{HCl}$ (Invitrogen Life Technologies, Carlsbad, CA, USA) for 1-2 $\mathrm{h}$ at room temperature, and then incubated with anti-iNOS (cat. no. 2982; 1:500; Cell Signaling Technology, Inc., Danvers, MA, USA) and anti- $\beta$-actin (cat. no. sc-47778; 1:2,000; Santa Cruz Biotechnology, Inc., Dallas, TX, USA), at $4^{\circ} \mathrm{C}$ overnight. After three washes with Tris-buffered saline containing Tween 20 , the membranes were incubated with horseradish peroxidase-labeled goat anti-rabbit immunoglobulin G (1:5,000; Santa Cruz Biotechnology, Inc.) at room temperature for $2 \mathrm{~h}$. The bound antibodies were visualized using an enhanced chemiluminescence system (Pierce Biotechnology Inc., Rockford, IL, USA) and exposed to X-ray film. $\beta$-actin was used as an internal reference for relative quantification. The expression levels of each sample were analyzed using Image-Pro plus software 6.0 (Media Cybernetics, Inc., Rockville, MD, USA).

iNOS activity assay. iNOS activity in the ischemic myocardium was determined using an NOS assay kit (Nanjing Jiancheng Bioengineering Institute) (26). Myocardium samples (100-120 mg) were separated from the anterior wall of the left ventricle and placed in a centrifuge tube, alongside $\sim 10$ volumes of ice-cold phosphate-buffered saline ( $\mathrm{pH} 7.4$; BeastBio). The tissue was homogenized for 1-2 min on ice and centrifuged at $1,200 \mathrm{x} \mathrm{g}$ for $15 \mathrm{~min}$ at $4^{\circ} \mathrm{C}$. The supernatant was collected and stored at $-80^{\circ} \mathrm{C}$ until further use. The protein concentration was measured using a BCA assay. The supernatant was then

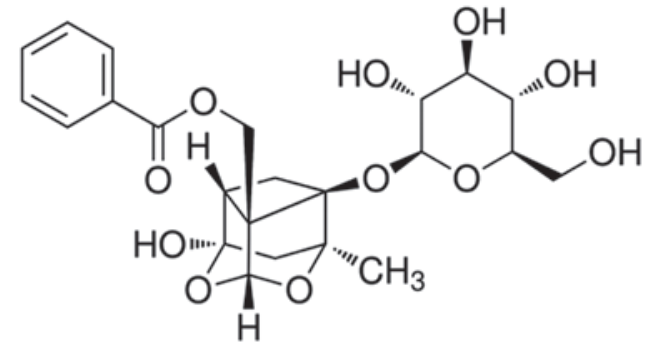

Figure 1. Chemical structure of paeoniflorin.

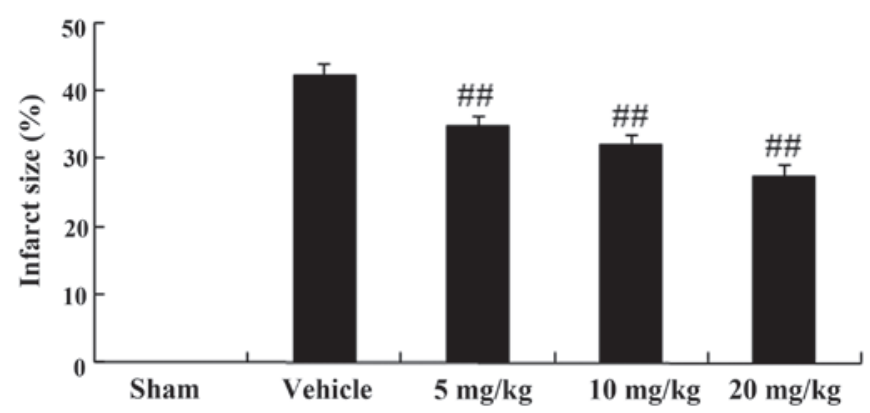

Figure 2. Infarct size in a rat model of acute myocardial infarction. The values are expressed as the mean \pm standard deviation. ${ }^{\# \#} \mathrm{P}<0.01$ vs. the vehicle group.

incubated with $0.6 \mathrm{ml}$ reaction buffer and $1 \mathrm{mmol} / 1$ ethylene glycol tetraacetic acid (BeastBio) for $15 \mathrm{~min}$ at $37^{\circ} \mathrm{C}$. iNOS activity was determined using the plate reader (Infinite M200; Tecan, Männedorf, Switzerland) by measuring the absorbance at a wavelength of $530 \mathrm{~nm}$.

Caspase-3 and caspase-9 activity assays. Caspase-3 and caspase- 9 activities were measured by cleavage of chromogenic caspase substrates, acetyl-Asp-Glu-Val-Asp p-nitroanilide (Ac-deVd-pnA), caspase-3 and caspase-9 substrate. The activities of caspase- 3 and caspase- 9 were determined using caspase- 3 and caspase- 9 colorimetric assay kits (Beyotime Institute of Biotechnology), according to the manufacturer's instructions. Cardiac cytosolic protein $(\sim 50 \mu \mathrm{g})$ was incubated in a solution buffer at $37^{\circ} \mathrm{C}$ for $30 \mathrm{~min}$. The caspase reaction was then initiated by adding $2 \mathrm{mM}$ Ac-DEVD-pNA, and the samples were incubated at $37^{\circ} \mathrm{C}$ for $4 \mathrm{~h}$. The change in fluorescence (excitation, $400 \mathrm{~nm}$ ) was detected at a wavelength of $405 \mathrm{~nm}$.

Statistical analysis. All data were analyzed by SPSS 17.0 software (SPSS, Inc., Chicago, IL, USA) and are presented as the mean \pm standard deviation. Differences were analyzed by one-way analysis of variance, followed by Dunnett's test for individual comparisons between each group. $\mathrm{P}<0.05$ was considered to indicate a statistically significant difference.

\section{Results}

Infarct size in a rat model of $A M I$. The infarct size in the vehicle group was $42.15 \pm 2.11 \%$. Following treatment with $\mathrm{PF}$ $(5,10$ and $20 \mathrm{mg} / \mathrm{kg})$, the infarct size was significantly reduced to $34.86 \pm 1.61 \%(\mathrm{P}<0.01 ; \mathrm{n}=6), 31.94 \pm 1.79 \%(\mathrm{P}<0.01 ; \mathrm{n}=6)$ and 
Table I. Activities of CK, CK-MB and LDH, and levels of cTnT in a rat model of AMI.

\begin{tabular}{lcccc}
\hline Group & CK $(\mathrm{U} / \mathrm{ml})$ & CK-MB (IU/l) & LDH $(\mathrm{U} / \mathrm{l})$ & $\mathrm{cTnT}(\mathrm{U} / \mathrm{ml})$ \\
\hline Sham & $0.25 \pm 0.04$ & $82.36 \pm 6.98$ & $1698.69 \pm 342.21$ & $0.08 \pm 0.04$ \\
Vehicle & $0.87 \pm 0.07^{\mathrm{a}}$ & $199.02 \pm 8.97^{\mathrm{a}}$ & $5731.63 \pm 421.13^{\mathrm{a}}$ & $0.51 \pm 0.08^{\mathrm{a}}$ \\
PF $(5 \mathrm{mg} / \mathrm{kg})$ & $0.43 \pm 0.04^{\mathrm{c}}$ & $114.52 \pm 7.86^{\mathrm{c}}$ & $3125.74 \pm 308.53^{\mathrm{b}}$ & $0.17 \pm 0.06^{\mathrm{c}}$ \\
PF $(10 \mathrm{mg} / \mathrm{kg})$ & $0.35 \pm 0.05^{\mathrm{c}}$ & $97.26 \pm 8.96^{\mathrm{c}}$ & $2712.42 \pm 377.42^{\mathrm{c}}$ & $0.15 \pm 0.04^{\mathrm{c}}$ \\
PF $(20 \mathrm{mg} / \mathrm{kg})$ & $0.30 \pm 0.03^{\mathrm{c}}$ & $85.72 \pm 6.69^{\mathrm{c}}$ & $2289.37 \pm 358.93^{\mathrm{c}}$ & $0.13 \pm 0.04^{\mathrm{c}}$ \\
\hline
\end{tabular}

Values are expressed as the mean \pm standard deviation $(\mathrm{n}=6) .{ }^{\mathrm{a}} \mathrm{P}<0.01 \mathrm{vs}$. sham group, ${ }^{\mathrm{b}} \mathrm{P}<0.05,{ }^{\mathrm{c}} \mathrm{P}<0.01$ vs. vehicle group. Sham, sham-operated; Vehicle, vehicle-treated. PF, paeoniflorin; AMI, acute myocardial infarction; CK, creatine kinase; CK-MB, MB isoenzyme of CK; LDH, lactate dehydrogenase; cTnT, cardiac troponin.
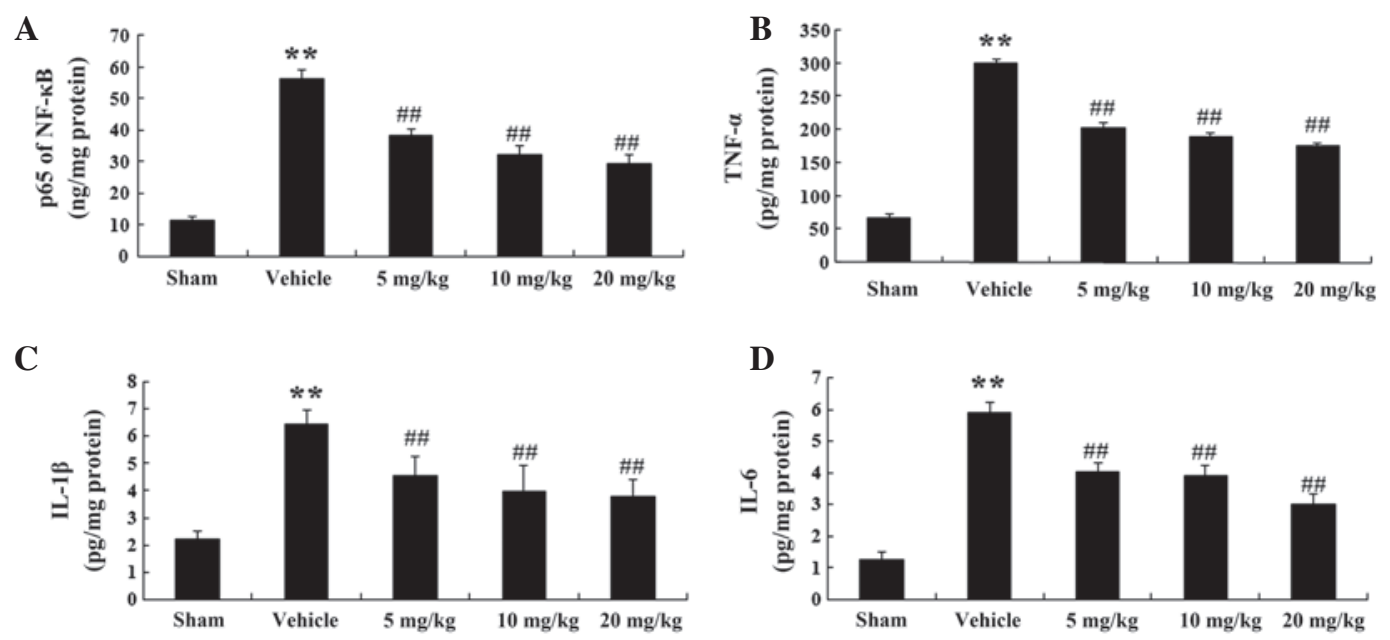

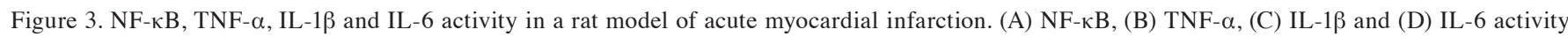
in the various groups. Values are expressed as the mean \pm standard deviation $(\mathrm{n}=6)$. ${ }^{* * *} \mathrm{P}<0.01$ vs. the sham group; ${ }^{\# \#} \mathrm{P}<0.01$ vs. the vehicle group. Sham, sham-operated; Vehicle, vehicle-treated; $5 \mathrm{mg} / \mathrm{kg}, \mathrm{PF}(5 \mathrm{mg} / \mathrm{kg}$ )-treated; $10 \mathrm{mg} / \mathrm{kg}, \mathrm{PF}$ (10 mg/kg)-treated and $10 \mathrm{mg} / \mathrm{kg}, \mathrm{PF}(20 \mathrm{mg} / \mathrm{kg})$-treated groups. NF-kB, nuclear factor- $\mathrm{kB}$; TNF- $\alpha$, tumor necrosis factor- $\alpha$; IL, interleukin; PF, paeoniflorin.

$27.43 \pm 1.89 \%(\mathrm{P}<0.01 ; \mathrm{n}=6)$, respectively, as compared with that in the vehicle group (Fig. 2).

$C K, C K-M B, L D H$ and cTnT levels in a rat model of AMI. The levels of serum CK, CK-MB, LDH and cTnT in the sham, vehicle and PF-treated $(5,10$ and $20 \mathrm{mg} / \mathrm{kg})$ groups are summarized in Table I. The levels of CK, CK-MB, LDH and cTnT were significantly increased in the serum of the operated rats $(\mathrm{P}<0.01, \mathrm{n}=6)$, as compared with those in the sham group. Pre-treatment with $\mathrm{PF}$ at $5 \mathrm{mg} / \mathrm{kg}(\mathrm{P}<0.01 ; \mathrm{n}=6), 10 \mathrm{mg} / \mathrm{kg}$ $(\mathrm{P}<0.01 ; \mathrm{n}=6)$ and $20 \mathrm{mg} / \mathrm{kg}(\mathrm{P}<0.01, \mathrm{n}=6)$ markedly reduced the levels of CK, CK-MB, LDH and cTnT in the serum of the AMI rat model as compared with those in the vehicle group.

TNF- $\alpha, I L-1 \beta, I L-6$ and $N F-\kappa B$ activities in a rat model of $A M I$. In order to corroborate the effects of $\mathrm{PF}$ on the inflammatory mediators in a rat model of AMI, the activities of $\mathrm{NF}-\kappa \mathrm{B}$, TNF- $\alpha$, IL-1 $\beta$ and IL-6 were evaluated (Fig. 3A-D). NF- $\kappa$ B activity was enhanced in the vehicle group to $56.11 \pm 3.28 \mathrm{ng} / \mathrm{mg}$ protein $(\mathrm{P}<0.01 ; \mathrm{n}=6)$, as compared with $11.8 \pm 1.03 \mathrm{ng} / \mathrm{mg}$ protein in the sham group (Fig. 3A). Following treatment with $\mathrm{PF}(5,10$ and $20 \mathrm{mg} / \mathrm{kg}), \mathrm{NF}-\kappa \mathrm{B}$ activity was markedly decreased to $38.21 \pm 2.29(\mathrm{P}<0.01 ; \mathrm{n}=6), 32.25 \pm 2.89(\mathrm{P}<0.01$; $\mathrm{n}=6)$ and $29.18 \pm 3.01 \mathrm{ng} / \mathrm{mg}$ protein $(\mathrm{P}<0.01 ; \mathrm{n}=6)$ respectively, as compared with that in the vehicle group $(56.11 \pm 3.28 \mathrm{ng} / \mathrm{mg}$ protein) (Fig. 3A).

Similarly, TNF- $\alpha$ activity in the vehicle group was markedly increased to $299.42 \pm 8.03 \mathrm{pg} / \mathrm{mg}$ protein $(\mathrm{P}<0.01$; $\mathrm{n}=6)$ as compared with that in the sham group $(66.87 \pm 6.32$ $\mathrm{pg} / \mathrm{mg}$ protein) (Fig. 3B). In the PF treatment groups (5, 10 and $20 \mathrm{mg} / \mathrm{kg}$ ), TNF- $\alpha$ activity was significantly reduced to 202.13 $\pm 9.11(\mathrm{P}<0.01 ; \mathrm{n}=6), 187.8 \pm 8.41(\mathrm{P}<0.01 ; \mathrm{n}=6)$ and $175.32 \pm 6.32 \mathrm{pg} / \mathrm{mg}$ protein $(\mathrm{P}<0.01 ; \mathrm{n}=6)$, respectively, as compared with that in the vehicle group $(299.42 \pm 8.03 \mathrm{pg} / \mathrm{mg}$ protein) (Fig. 3B).

Furthermore, IL-1 $\beta$ activity in the vehicle group was markedly elevated to $6.46 \pm 0.52 \mathrm{pg} / \mathrm{mg}$ protein $(\mathrm{P}<0.01, \mathrm{n}=6)$, as compared with that in the sham group $(2.22 \pm 0.28 \mathrm{pg} / \mathrm{mg}$ protein $)$ (Fig. 3C). In the PF treatment groups (5, 10 and $20 \mathrm{mg} / \mathrm{kg})$, IL-1 $\beta$ activity was significantly decreased to $4.53 \pm 0.71(\mathrm{P}<0.01$; $\mathrm{n}=6), 3.99 \pm 0.93(\mathrm{P}<0.01 ; \mathrm{n}=6)$ and $3.78 \pm 0.62 \mathrm{pg} / \mathrm{mg}$ protein $(\mathrm{P}<0.01 ; \mathrm{n}=6)$, respectively, as compared with that in the vehicle group (6.46 $\pm 0.52 \mathrm{pg} / \mathrm{mg}$ protein) (Fig. 3C).

In addition, IL- 6 activity in the vehicle group was significantly increased to $5.89 \pm 0.32 \mathrm{pg} / \mathrm{mg}$ protein $(\mathrm{P}<0.01, \mathrm{n}=6)$ as compared with that in the sham group $(1.28 \pm 0.21 \mathrm{pg} / \mathrm{mg}$ protein $)$ 
A

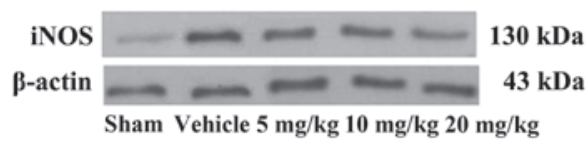

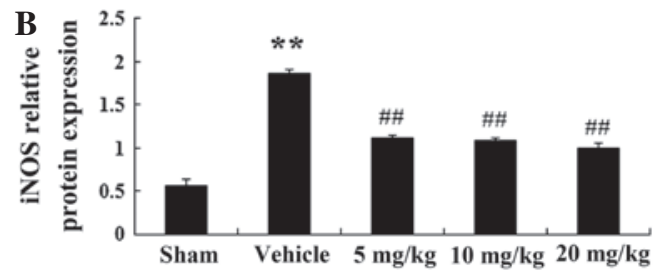

C

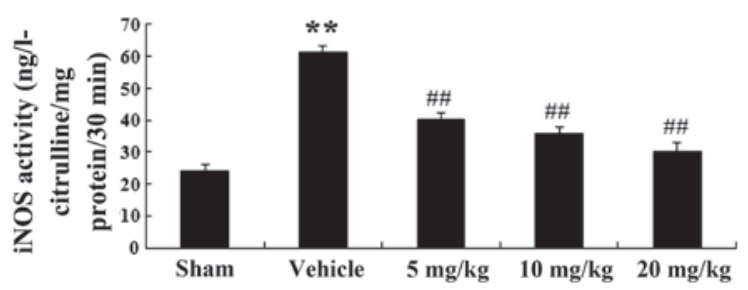

Figure 4. Protein expression levels of iNOS and iNOS activity in a rat model of acute myocardial infarction. (A) Representative western blots showing iNOS protein expression. (B) Quantification of the relative protein expression levels of iNOS. (C) iNOS activity in the various groups. Values are expressed as the mean \pm standard deviation $(\mathrm{n}=6) .{ }^{* *} \mathrm{P}<0.01$ vs. the sham group; ${ }^{\#} \mathrm{P}<0.01$ vs. the vehicle group. Sham, sham-operated; Vehicle, vehicle-treated; $5 \mathrm{mg} / \mathrm{kg}, \mathrm{PF}$ (5 mg/kg)-treated, $10 \mathrm{mg} / \mathrm{kg}$, PF (10 mg/kg)-treated and $10 \mathrm{mg} / \mathrm{kg}$, PF (20 mg/kg)-treated groups. iNOS, inducible nitric oxide synthase; PF, paeoniflorin.

A
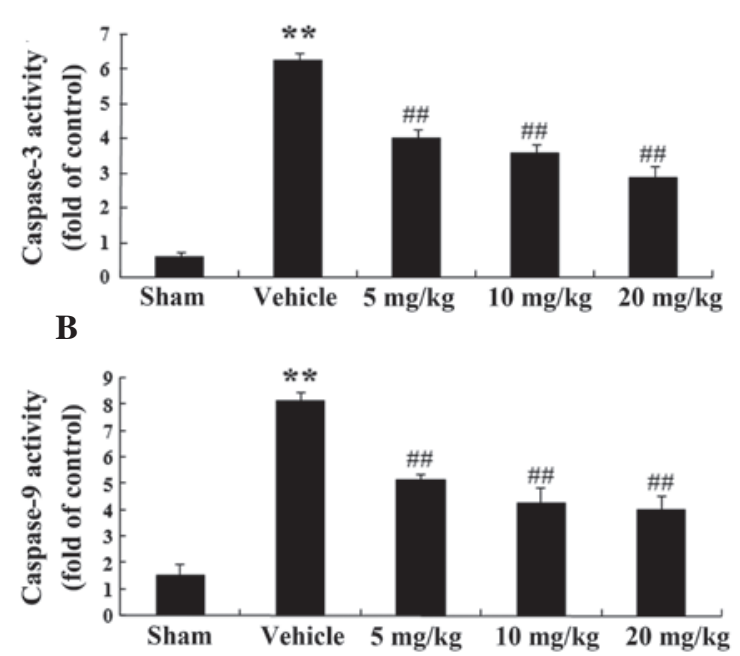

Figure 5. Caspase-3 and caspase-9 activity in a rat model of acute myocardial infarction. (A) Caspase-3 and (B) caspase-9 activity was determined in the various groups. Values are expressed as the mean \pm standard deviation $(n=6) .{ }^{* *} \mathrm{P}<0.01$ vs. the sham group; ${ }^{\# \#} \mathrm{P}<0.01$ vs. the vehicle group. Sham, sham-operated; Vehicle, vehicle-treated; $5 \mathrm{mg} / \mathrm{kg}, \mathrm{PF}(5 \mathrm{mg} / \mathrm{kg})$-treated, $10 \mathrm{mg} / \mathrm{kg}, \mathrm{PF}(10 \mathrm{mg} / \mathrm{kg})$-treated and $10 \mathrm{mg} / \mathrm{kg}, \mathrm{PF}(20 \mathrm{mg} / \mathrm{kg})$-treated groups. $\mathrm{PF}$, paeoniflorin.

(Fig. 3D). In the PF treatment groups (5, 10 and $20 \mathrm{mg} / \mathrm{kg})$, IL-6 activity was significantly decreased to $4.01 \pm 0.31(\mathrm{P}<0.01$; $\mathrm{n}=6), 3.89 \pm 0.33(\mathrm{P}<0.01 ; \mathrm{n}=6)$ and $0.33 \pm 0.33 \mathrm{pg} / \mathrm{mg}$ protein $(\mathrm{P}<0.01 ; \mathrm{n}=6)$ as compared with that in the vehicle group (45.26 $\pm 0.65 \mathrm{pg} / \mathrm{mg}$ protein) (Fig. 3D).

Protein expression levels of iNOS and iNOS activity in a rat model of AMI. The protein expression levels of iNOS were determined in the rat model of AMI using western blot analysis. iNOS expression was detected in bands located at $130 \mathrm{kDa}$ (Fig. 4A). The protein expression levels of iNOS were significantly increased in the vehicle group $(\mathrm{P}<0.01 ; \mathrm{n}=6)$, as compared with those in the sham group. In addition, the protein expression levels of iNOS were markedly decreased following treatment with $\mathrm{PF}$ at $5 \mathrm{mg} / \mathrm{kg}(\mathrm{P}<0.01 ; \mathrm{n}=6), 10 \mathrm{mg} / \mathrm{kg}(\mathrm{P}<0.01$; $\mathrm{n}=6)$ and $20 \mathrm{mg} / \mathrm{kg}(\mathrm{P}<0.01 ; \mathrm{n}=6)$, as compared with those in the vehicle group (Fig. 4B).

Furthermore, iNOS activity in the vehicle group was markedly elevated to $61.35 \pm 2.23 \mathrm{ng}$ L-citrulline $/ \mathrm{mg}$ protein $/ 30 \mathrm{~min}$ $(\mathrm{P}<0.01 ; \mathrm{n}=6)$, as compared with that in the sham group (24.18 $\pm 2.14 \mathrm{ng}$ L-citrulline/mg protein/30 min) (Fig. 4C). In the PF treatment groups $(5,10$ and $20 \mathrm{mg} / \mathrm{kg})$, iNOS activity was significantly decreased to $40.25 \pm 2.19$ ( $\mathrm{P}<0.01$; $\mathrm{n}=6) 35.89 \pm 2.25(\mathrm{P}<0.01 ; \mathrm{n}=6)$ and $30.11 \pm 3.24 \mathrm{ng}$ L-citrulline/mg protein $/ 30 \mathrm{~min}(\mathrm{P}<0.01 ; \mathrm{n}=6)$ as compared with that in the vehicle-treated group $(61.35 \pm 2.23 \mathrm{ng}$ L-citrulline/mg protein/30 min) (Fig. 4C).

Caspase-3 and caspase-9 activity in a rat model of AMI. A colorimetric analysis was conducted, and PF was shown to decrease the activity of caspase-3 (Fig. 5A). Caspase-3 activity in the vehicle group was markedly increased by $6.26 \pm 0.18$ $(\mathrm{P}<0.01 ; \mathrm{n}=6)$, as compared with that in the sham group. In the PF treatment groups $(5,10$ and $20 \mathrm{mg} / \mathrm{kg})$, there was a marked decline in caspase-3 activity by $4.02 \pm 0.22(\mathrm{P}<0.01$; $\mathrm{n}=6), 3.56 \pm 0.24(\mathrm{P}<0.01 ; \mathrm{n}=6)$ and $2.89 \pm 0.31(\mathrm{P}<0.01 ; \mathrm{n}=6)$ respectively, as compared with that in the vehicle-treated group (Fig. 5A).

In addition, treatment with $\mathrm{PF}$ was able to decrease caspase-9 activity (Fig. 5B). Caspase-9 activity in the vehicle group was significantly increased by $8.12 \pm 0.34(\mathrm{P}<0.01, \mathrm{n}=6)$, as compared with that in the sham group. In the PF treatment groups $(5,10$ and $20 \mathrm{mg} / \mathrm{kg})$, there was a marked decrease in caspase-9 activity by $5.12 \pm 0.27(\mathrm{P}<0.01 ; \mathrm{n}=6), 4.25 \pm 0.61$ $(\mathrm{P}<0.01 ; \mathrm{n}=6)$ and $3.99 \pm 0.58(\mathrm{P}<0.01 ; \mathrm{n}=6)$, respectively, as compared with that in the vehicle-treated group (Fig. 5B).

\section{Discussion}

PF is the main active component of the commonly used Traditional Chinese Medicine peony, Paeonia Suffruticosa, which exhibits anti-oxidative, anti-inflammatory and anti-apoptotic activities. Previous studies have demonstrated that PF is 
able to significantly reduce the expression levels of NF- $\kappa \mathrm{B}$ and B-cell lymphoma-2 in a dose-dependent manner (18,19,27). PF has a protective effect on the blood-brain barrier after cerebral ischemia, local cerebral blood flow and brain edema. It has also been indicated that PF has a significant protective effect on focal cerebral ischemic injury. It has been suggested that PF may inhibit intracellular calcium and free radical overload, and improve cerebral vasomotor dysfunction caused by ischemia and anoxia. Furthermore, PF is able to protect the blood-brain barrier following cerebral perfusion during ischemia, and promote the recovery of cerebral blood flow in the early period of reperfusion. PF can also reduce iNOS, TNF- $\alpha$, IL- $\beta$ and IL-6 activation. The results of the present study demonstrated that treatment with PF had a cardioprotective effect in a rat model of AMI, which may be associated with modulation of inflammation and iNOS signaling pathways.

The infarct size of AMI and the presence of myocardial specific enzymes (CK, CK-MB, LDH and cTnT) are regarded as important indices for assessing the cardiac damage caused by AMI. Numerous studies have indicated that CK, CK-MB and cTnT are widely spread over the cytoplasm of myocardial cells, and the activities of CK, CK-MB and cTnT in rats underwent AMI (27-29). cTnT activity is a more sensitive and specific marker of AMI in rats, as compared with CK-MB (30). The levels of $\mathrm{LDH}$ in the culture supernatant are a very sensitive and specific indicator for detecting AMI. However, LDH is a less sensitive and specific marker of AMI in rats, as compared with CK-MB, and has also been observed in non-cardiac conditions (31). The present study demonstrated that treatment with PF was able to decrease the myocardial infarct size as well as CK, CK-MB, LDH and cTnT activities in a rat model of AMI, thus suggesting that PF exerts cardioprotective effects on AMI.

Recent studies have suggested that the inflammatory response has an important role throughout the development and progression of ischemic heart disease. It is well known that NF- $\kappa \mathrm{B}$, which is an inflammatory factor in cardiac tissues during AMI, is a transcription factor associated with various biological processes (32). NF- $\kappa \mathrm{B}-\mathrm{p} 65$ is the primary trans-activating transcriptional activator of $\mathrm{NF}-\kappa \mathrm{B}$ and has regulatory functions in the inflammatory process (33). Pro-inflammatory cytokines have been shown to be upregulated during AMI, with TNF- $\alpha$, IL-1 $\beta$ and IL- 6 being the most important (34). Activation of TNF- $\alpha$, IL- $1 \beta$ and IL- 6 is modulated by NF- $\kappa$ B. TNF- $\alpha$ can increase the phagocytosis of neutrophils and also promote the secretion of IL- $1 \beta$ and IL- 6 from endothelial cells. TNF- $\alpha$, IL- $1 \beta$ and IL- 6 are synthesized rapidly and released by immune cells in rat models of AMI. The results of the present study demonstrated that treatment with PF was able to attenuate the excessive activation of $\mathrm{NF}-\kappa \mathrm{B}$ and the release of TNF- $\alpha$, IL- $1 \beta$ and IL- 6 in a rat model of AMI. Previous studies have also suggested that $\mathrm{PF}$ may significantly reduce the expression of NF- $\kappa \mathrm{B}, \mathrm{TNF}-\alpha, \mathrm{IL}-1$ and IL-6 $(17,27)$. These findings indicated that treatment with PF may have a cardioprotective anti-inflammatory effect following AMI.

NOS is a catalytic enzyme which synthesizes NO, and $\mathrm{NO}$ is known to have a wide range of important physiological and pathological functions. NO has an important regulatory role in the cardiovascular, immune, nervous and digestive systems (35). Due to the reactivity and short half-life of NO, numerous studies have focused on NOS. Although NO is able to maintain mucosal vasodilation and vascular permeability, excessive NO can also directly cause cell toxicity and lead to peroxidation, causing tissue damage. TNF- $\alpha$, IL-1 $\beta$, IL- 6 , and $\mathrm{NF}-\kappa \mathrm{B}$ are able to stimulate the cells in blood vessel walls to express iNOS, which is accompanied by the release of NO and a decline in vascular tension $(36,37)$. These cytokines increase the catalytic activity of iNOS through transcriptional, post-transcriptional and translational regulation, and affect signal transduction pathways, in order to promote NO synthesis. Following myocardial infarction in mice, increased expression of iNOS has been detected, resulting in the induction of excessive NO, which decreases cardiac function and increases the risk of mortality. The results of the present study demonstrated that treatment with PF was able to reduce AMI-induced inflammation and iNOS signaling.

Recent studies have confirmed that the activation of caspase- 3 and caspase- 9 is critical in the course of intrinsic apoptosis (36). The initiation of caspase-3 occurred at day 3 , and was significantly increased until day 7 . The expression levels of caspase- 9 have previously been shown to be elevated 7 days after cardiac damage (38). The results of the present study indicated that treatment with PF markedly reduced caspase-3 and caspase- 9 activity. Furthermore, the activities of caspase- 3 and caspase- 9 were markedly reduced by PF treatment. In agreement with the findings of the present study, PF treatment was previously shown to significantly decrease caspase- 3 and caspase-9 activity in Alzheimer's disease (39).

In conclusion, the present study demonstrated that PF treatment was able to attenuate the damage caused by AMI. The cardioprotective effects of PF may be associated with inhibition of inflammation and iNOS signaling. The present study was the first, to the best of our knowledge, to identify the protective action and the potential protective mechanism of $\mathrm{PF}$ in a rat model of AMI. These results provided evidence that PF may be a potential cardioprotective agent for the treatment of AMI.

\section{Acknowledgements}

This study was supported by the National Natural Science Foundation of China (grant no. 81200173) and Liaoning Province Science and Technology Plan Projects (grant no. 2013023026).

\section{References}

1. Ouyang J, Guzman M, Desoto-Lapaix F, Pincus MR and Wieczorek R: Utility of desmin and a Masson's trichrome method to detect early acute myocardial infarction in autopsy tissues. Int J Clin Exp Pathol 3: 98-105, 2009.

2. Zhang S, Liu X, Goldstein S, et al: Role of the JAK/STAT signaling pathway in the pathogenesis of acute myocardial infarction in rats and its effect on NF-кB expression. Mol Med Rep 7: 93-98, 2013.

3. Smith RS Jr, Agata J, Xia CF, et al: Human endothelial nitric oxide synthase gene delivery protects against cardiac remodeling and reduces oxidative stress after myocardial infarction. Life Sci 76: 2457-2471, 2005.

4. Yan KP, Guo Y, Xing Z, et al: Dan-Shen-Yin protects the heart against inflammation and oxidative stress induced by acute ischemic myocardial injury in rats. Exp Ther Med 3: 314-318, 2012.

5. Kain V, Ingle KA, Colas RA, et al: Resolvin D1 activates the inflammation resolving response at splenic and ventricular site following myocardial infarction leading to improved ventricular function. J Mol Cell Cardiol 84: 24-35, 2015. 
6. Hotamisligil GS, Shargill NS and Spiegelman BM: Adipose expression of tumor necrosis factor-alpha: Direct role in obesity-linked insulin resistance. Science 259: 87-91, 1993.

7. Hotamisligil GS, Arner P, Caro JF, et al: Increased adipose tissue expression of tumor necrosis factor-alpha in human obesity and insulin resistance. J Clin Invest 95: 2409-2415, 1995.

8. Cheng P, Wang F, Chen K, et al: Hydrogen sulfide ameliorates ischemia/reperfusion-induced hepatitis by inhibiting apoptosis and autophagy pathways. Mediators Inflamm 2014: 935251, 2014.

9. Ramachandran S, Liaw JM, Jia J, et al: Ischemia-reperfusion injury in rat steatotic liver is dependent on NFкB P65 activation. Transp Immunol 26: 201-206, 2012.

10. Furchgott RF and Zawadzki JV: The obligatory role of endothelial cells in the relaxation of arterial smooth muscle by acetylcholine. Nature 288: 373-376, 1980.

11. Palmer RM, Ferrige AG and Moncada S: Nitric oxide release accounts for the biological activity of endothelium-derived relaxing factor. Nature 327: 524-526, 1987.

12. Jugdutt BI: Nitric oxide and cardioprotection during ischemia-reperfusion. Heart Fail Rev 7: 391-405, 2002.

13. Crowell JA, Steele VE, Sigman CC and Fay JR: Is inducible nitric oxide synthase a target for chemoprevention? Mol Cancer Ther 2: 815-823, 2003

14. Chen C, Zhang F, Xia ZY, et al: Protective effects of pretreatment with Radix Paeoniae Rubra on acute lung injury induced by intestinal ischemia/reperfusion in rats. Chin J Traumatol 11: 37-41, 2008.

15. Khan M, Mohan IK, Kutala VK, et al: Sulfaphenazole protects heart against ischemia-reperfusion injury and cardiac dysfunction by overexpression of iNOS, leading to enhancement of nitric oxide bioavailability and tissue oxygenation. Antioxid Redox Signal 11: 725-738, 2009

16. Sun R, Yi YP, Lv LL, Zhang ZP, Sun H and Liu GQ: Effects of paeoniflorin on pathological changes in global brain ischemia model rats. Zhongguo Zhong Yao Za Zhi 32: 2518-2522, 2007 (In Chinese)

17. Ding MP, Feng F and Hu HT: Effects of puerarin on expression of nuclear factor kappaB after cerebral ischemia/reperfusion in rats. Zhongguo Zhong Yao Za Zhi 32: 2515-2518, 2007 (In Chinese).

18. Hu W, Zhang Q, Yang X, et al: Puerarin inhibits adhesion molecule expression in tnf-alpha-stimulated human endothelial cells via modulation of the nuclear factor kappaB pathway. Pharmacology 85 $27-35,2010$

19. Hino H, Takahashi H, Suzuki Y, et al: Anticonvulsive effect of paeoniflorin on experimental febrile seizures in immature rats: Possible application for febrile seizures in children. PLoS One 7: e42920, 2012

20. Li S, Korkmaz S, Loganathan S, et al: Acute ethanol exposure increases the susceptibility of the donor hearts to ischemia/reperfusion injury after transplantation in rats. PLoS One 7: e49237, 2012

21. Uchida Y, Freitas MC, Zhao D, et al: The protective function of neutrophil elastase inhibitor in liver ischemia/reperfusion injury. Transplantation 89: 1050-1056, 2010.

22. Camilleri JP, Joseph D, Fabiani JN, et al: Microcirculatory changes following early reperfusion in experimental myocardial infarction. Virchows Arch A Pathol Anat Histol 369: 315-333, 1976.

23. Hoda MN, Li W, Ahmad A, et al: Sex-independent neuroprotection with minocycline after experimental thromboembolic stroke. Exp Transl Stroke Med 3: 16, 2011.

24. Hoda MN, Siddiqui S, Herberg S, et al: Remote ischemic perconditioning is effective alone and in combination with intravenous tissue-type plasminogen activator in murine model of embolic stroke. Stroke 43: 2794-2799, 2012.
25. Ikeda U, Ikeda M, Minota S and Shimada K: Homocysteine increases nitric oxide synthesis in cytokine-stimulated vascular smooth muscle cells. Circulation 99: 1230-1235, 1999.

26. Ashokkumar P and Sudhandiran G: Luteolin inhibits cell proliferation during Azoxymethane-induced experimental colon carcinogenesis via Wnt $/ \beta$-catenin pathway. Invest New Drugs 29: 273-284, 2011.

27. Guo RB, Wang GF, Zhao AP, et al: Paeoniflorin protects against ischemia-induced brain damages in rats via inhibiting MAPKs/NF- $\kappa$ B-mediated inflammatory responses. PLoS One 7: e49701, 2012.

28. Guo J, Li HZ, Wang LC, et al: Increased expression of calcium-sensing receptors in atherosclerosis confers hypersensitivity to acute myocardial infarction in rats. Mol Cell Biochem 366: 345-354, 2012.

29. Ming X, Tongshen W, Delin W and Ronghua Z: Cardioprotective effect of the compound yangshen granule in rat models with acute myocardial infarction. Evid Based Complement Alternat Med 2012: 717123, 2012.

30. Priscilla DH and Prince PS: Cardioprotective effect of gallic acid on cardiac troponin-T, cardiac marker enzymes, lipid peroxidation products and antioxidants in experimentally induced myocardial infarction in Wistar rats. Chem Biol Interact 179: 118-124, 2009.

31. Shah $\mathrm{H}$ and Haridas N: Evaluation of clinical utility of serum enzymes and troponin- $\mathrm{T}$ in the early stages of acute myocardial infarction. Indian J Clin Biochem 18: 93-101, 2003.

32. Sheu JJ, Sung PH, Leu S, et al: Innate immune response after acute myocardial infarction and pharmacomodulatory action of tacrolimus in reducing infarct size and preserving myocardial integrity. J Biomed Sci 20: 82, 2013.

33. Dong D, Xu L, Han X, et al: Effects of the total saponins from Rosa laevigata Michx fruit against acetaminophen-induced liver damage in mice via induction of autophagy and suppression of inflammation and apoptosis. Molecules 19: 7189-7206, 2014.

34. Talasaz AH, Khalili H, Jenab Y, et al: $N$-Acetylcysteine effects on transforming growth factor- $\beta$ and tumor necrosis factor- $\alpha$ serum levels as pro-fibrotic and inflammatory biomarkers in patients following ST-segment elevation myocardial infarction. Drugs R D 13: 199-205, 2013.

35. Liu YF, Tu SH, Chen Z, et al: Effects of modified simiao decoction on IL-1 $\beta$ and TNF $\alpha$ secretion in monocytic THP-1 cells with monosodium urate crystals-induced inflammation. Evid Based Complement Alternat Med 2014: 406816, 2014.

36. Liu Y, He P, Zhang M and Wu D: Lentiviral vector-mediated RNA interference targeted against prohibitin inhibits apoptosis of the retinoic acid-resistant acute promyelocytic leukemia cell line NB4-R1. Mol Med Rep 6: 1288-1292, 2012.

37. Jiang P, Li C, Xiang Z and Jiao B: Tanshinone IIA reduces the risk of Alzheimer's disease by inhibiting iNOS, MMP-2 and NF- $\mathrm{Bp} 65$ transcription and translation in the temporal lobes of rat models of Alzheimer's disease. Mol Med Rep 10 689-694, 2014

38. Feng J, Tao T, Yan W, et al: Curcumin inhibits mitochondrial injury and apoptosis from the early stage in EAE mice. Oxid Med Cell Longev 2014: 728751, 2014.

39. Wang K, Zhu L, Zhu X, et al: Protective effect of paeoniflorin on A $325-35$-induced SH-SY5Y cell injury by preventing mitochondrial dysfunction. Cell Mol Neurobiol 34: 227-234, 2014. 